\title{
Epidemiological Comparison of Osteoporotic Hip Fractures in Spain and China: A Multicenter Study
}

\section{Shuai-Shuai Gao}

Xi'an Daxing Hospital

Luis C Capitan-Morales

Hospital Universitario Virgen Macarena

Yan-Jun Wang

Xi'an Daxing Hospital

Yong-Feng Yao

Xi'an Daxing Hospital

Ya-Hui Zhang

Xi'an Daxing Hospital

Aurelio Borrás Verdera

Hospital Universitario Virgen Macarena

Wen-Ting Zhang ( $\sim 724521882 @ q q . c o m$ )

University of Seville

\section{Research Article}

Keywords: epidemiology, hip fracture, osteoporosis, mortality.

Posted Date: August 19th, 2021

DOI: https://doi.org/10.21203/rs.3.rs-796173/v1

License: (a) This work is licensed under a Creative Commons Attribution 4.0 International License. Read Full License 


\section{Abstract}

Objective Compare the epidemiological differences of hip fracture patients in Spain and China.

Materials and Method This was a retrospective study. The study population came from patients with hip fractures who underwent surgery between January 1, 2017 and December 30, 2017 at the University Hospital Virgen Macarena (UHVM) in Seville, Spain and Xi'an Daxing Hospital (XDH) in Shaanxi Province, China. Through medical history review and telephone follow-up, the differences of demographic and anthropometric characteristics, lifestyle, personal medical history, variables related to injury, anesthesia, and surgery, length of stay in hospital, days of bed rest, and mortality of patients in the two hospitals were compared.

Results A total of 757 patients were enrolled, of which 426 were from UHVM and 331 were from XDH. The average age was $81.4 \pm 9.26$ years and $76.0 \pm 8.08$ years, respectively; the male and female distribution was $25.1 \%$ and $74.9 \%$ vs. $32.0 \%$ and $68.0 \%$. The average BMI of Spanish patients was higher than that of Chinese patients. The proportion of drinking and smoking among Spanish patients was significantly higher than that of Chinese patients $(p=0.000, p=0.000$, respectively).

The proportion of patients with $\geq 3$ comorbidities in Spain was higher than that in China $(p=0.002)$. The surgery delay time of Spanish patients was significantly longer than that of Chinese patients $(p=0.000)$. Spanish patients had a shorter hospital stay, but a longer time in bed. During the one-year follow-up, there were 81 deaths in Spain and 43 deaths in China $(p=0.026)$.

Conclusiones There are large epidemiological differences between hip fracture patients in Seville, Spain and Xi'an, China in terms of demographics, lifestyle, comorbidities, surgical methods, and mortality.

\section{Introduction}

Hip fracture, as a serious complication of osteoporosis, brings heavy nursing and economic burdens to patients, family members and society. With the acceleration of global aging, the number of hip fractures is increasing year by year[1]. According to reports, it is estimated that by 2050 , nearly 6.3 million hip fractures will occur every year in the world[2]. Worldwide, due to differences in culture, race, geography, economic level, etc., there are significant differences in the epidemiology of hip fractures, such as age, sex ratio, incidence, and mortality[3]. According to reports, Scandinavia has the highest incidence (439/105 inhabitants/year in Denmark, 420/10 5 inhabitants/year in Norway, 401/10 $0^{5}$ inhabitants/year in Sweden), and the lowest incidence are in Tunisia (50/10 5 inhabitants/year), Ecuador (55/10 5 inhabitants/year) and Morocco (69/105 inhabitants/year)[4].

Spain, as a developed country that it is, has a very high number of elderly people. According to data provided by Statistics National Institute, in 2020, the population over 65 years old was about 9.27 million, accounting for $19.58 \%$ (the total population was 47.35 million)[5]. This number will continue to increase in the next 30 years. In terms of epidemiology, Serra et al. analyzed data on hip fractures from 1996 to 1999 by the Ministry of Health. There were 130,414 cases over 65 years old, with a mean age of 82 years old, being $78 \%$ females. The total incidence rate was 517 cases/105 residents/year, of which 270 were males and 695 were females[6]. Herrera et al. conducted a multicenter study in 77 hospitals in Spain. They recorded 13,195 hip fracture patients over 60 years of age in 2002, with an average age of $81.4 \pm 8.1$ years, of which $74 \%$ were women. The overall average incidence rate was $694 / 10^{5}$ inhabitants, of which males were 417 and women were 913[7]. Another Spanish study showed that between 1999 and 2015, among people over 45 years of age with osteoporotic hip fractures, the average age was 83 years, of which $78 \%$ were women, and the overall incidence was $290 / 10^{5}$ people (428 for women; 134 for men), and it was found that during this period, the incidence of fractures decreased by $3.6 \%$ per year[8]. This is similar to the recent findings of Aguilar[9] and Rey et al[10]. In other words, the incidence of hip fractures in Spain seems to be on the decline. In the mortality report, the one-year mortality rate of hip fracture patients in Spain is more than $20-33 \% .[8,11]$. 
As the most populous developing country in the world, with the increase of life expectancy and the improvement in health care, the problem of aging in China is becoming more and more serious. China has a vast territory and the epidemiology of hip fractures varies. A large study of approximately 460 million Chinese residents found that the absolute number of hip fractures increased by approximately four times between 2012 and 2016 . However, the overall incidence rate is relatively stable, 149 cases per 100,000 inhabitants in 2012 and 137 cases per 100,000 inhabitants in 2016. The average age of hip fracture patients was $77.05 \pm 8.94$ years, of which $63.99 \%$ were female[12]. Indeed, by 2050, the total number of hip fractures in people over 65 in China is expected to be 1.3 million[13]. A recent meta-analysis showed that the one-year mortality rate for hip fracture patients in China was $13.96 \%[14]$.

As mentioned above, there are differences in the epidemiology and mortality of hip fractures between Spain and China. Therefore, this study aims to understand these differences in depth and reveal their causes as much as possible, so as to provide reference and help for the epidemiology, prevention and treatment of hip fractures.

\section{Materials And Method}

This was a retrospective study. The patients came from two different centers, one from the Department of Traumatology and Orthopedic Surgery of the University Hospital Virgen Macarena (UHVM), Seville, Spain, and the other from the Department of Traumatology and Orthopedic Surgery of the Xi'an Daxing Hospital (XDH), Shaanxi, China. The patients diagnosed with hip fracture had undergone surgical surgery during the period of time between January 1, 2017 and December 30, 2017. They were followed for one year after the surgical intervention. The variables to be compared include demographic and anthropometric characteristics, lifestyle, activity levels before fracture, personal medical history, variables related to injury, anesthesia and surgery, hospital stay, hospitalization costs, days of bed rest, mortality at one year, and Harris score. All the information of the study subjects was entered in a data collection sheet (Annex).

Inclusion criteria: $₫$ Age $\geq 50$ years old. $\otimes$ Hip fracture diagnosed by radiology. $\otimes$ The type of hip fracture is femoral neck

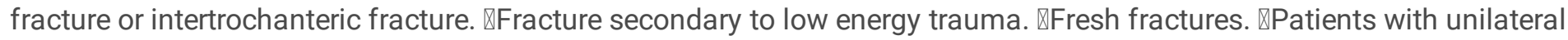
hip fractures. खPatients undergoing surgery. खPatients who have completed all follow-up data.

Exclusion criteria: खUnder 50 years of age. $\bigotimes$ The type of fracture is femoral head fracture or subtrochanteric fracture. \Fractures are secondary to high-energy trauma (falls from heights or traffic accidents). $\nabla$ Old fractures. खMultiple fractures. 『Pathological, fractures caused by other metabolic bone diseases, such as Paget's disease, primary or metastatic bone tumors, or chronic osteomyelitis. $\bowtie$ Patients receiving reservation treatment. $\otimes$ Patients with incomplete data.

\section{Statistical analysis}

SPSS22.0 statistical software was used for data analysis. The measurement data was expressed by mean \pm standard deviation $(\overline{\mathrm{x}} \pm \mathrm{s}$ ), and comparison between groups was by $\mathrm{t}$ test. The count data was expressed as the occurrence rate $\mathrm{n}(\%)$, and the $X^{2}$ test was used for comparison. In all these statistical tests, significance is considered when $p<0.05$; very significant when $p<0.01$, and highly significant when $p<0.001$.

\section{Results}

\section{The demographic and anthropometric characteristics of the patient}

A total of 757 patients were enrolled, of which 426 were from UHVM and 331 were from XDH. The proportion of Spanish women was higher than that of Chinese women, 319 (74.9\%) vs. $225(68.0 \%), p=0.036$. The average ages of Spanish and Chinese patients were $81.4 \pm 9.26$ years and $76.0 \pm 8.08$ years, respectively, with $p=0.000$. The average weights of Spanish and Chinese patients were $68.6 \pm 12.7 \mathrm{~kg}$ and $58.6 \pm 7.5 \mathrm{~kg}$, respectively, with $p=0.000$. Although there was no significant difference in the average height of Spanish and Chinese patients, $1.62 \pm 0.09 \mathrm{~m}$ and $1.61 \pm 0.07 \mathrm{~m}$, respectively, $p=0.082$, 
the average heights of Spanish men and women were higher than that of Chinese patients $(1.70 \pm 0.08 \mathrm{~m}$ vs. $1.68 \pm 0.05 \mathrm{~m}$ and $1,59 \pm 0.07 \mathrm{~m}$ vs. $1.58 \pm 0.05 \mathrm{~m}), \mathrm{p}=0.008$ and $\mathrm{p}=0.006$ respectively. For the comparison of Body Mass Index (BMI), the average BMI of Spanish and Chinese patients were $26.1 \pm 4.3$ and $22.6 \pm 2.0, p=0.000$. Regarding the type of BMI, more than half $(60.0 \%)$ of Spanish patients were overweight and obese, while Chinese patients with normal weight accounted for $87.9 \%, p=0.000$. The demographic and anthropometric characteristics are shown in Table 1.

Table 1

Demographic and anthropometric characteristics between Spain and China.

\begin{tabular}{|c|c|c|c|c|}
\hline & $\begin{array}{l}\text { Spain } \\
(n=426)\end{array}$ & $\begin{array}{l}\text { China } \\
(n=331)\end{array}$ & $\begin{array}{l}\text { test T / } \\
X^{2}\end{array}$ & Value P \\
\hline \multicolumn{5}{|c|}{ Demographic characteristics } \\
\hline Sex & & & 4.394 & $0.036^{\star}$ \\
\hline Men & $107(25.1 \%)$ & $106(32.0 \%)$ & & \\
\hline Woman & $319(74.9 \%)$ & $225(68.0 \%)$ & & \\
\hline Age (years) & $81.4 \pm 9.3$ & $76.0 \pm 8.1$ & 8.448 & $0.000 \star \star \star *$ \\
\hline Men & $80.0 \pm 10.2$ & $73.3 \pm 8.7$ & 5.106 & $0.000 * * *$ \\
\hline Woman & $81.9 \pm 8.9$ & $77.3 \pm 7.5$ & 6.614 & $0.000 * * \star$ \\
\hline \multicolumn{5}{|c|}{ Anthropometric characteristics } \\
\hline Weight (Kg) & $68.6 \pm 12.7$ & $58.6 \pm 7.5$ & 13.489 & $0.000 * * *$ \\
\hline Men & $72.6 \pm 11.1$ & $67.0 \pm 5.1$ & 4.785 & $0.000 * * *$ \\
\hline Woman & $67.3 \pm 12.9$ & $54.7 \pm 4.7$ & 15.932 & $0.000 \star \star \star *$ \\
\hline Height (m) & $1.62 \pm 0.09$ & $1.61 \pm 0.07$ & 1.740 & 0.082 \\
\hline Men & $1.70 \pm 0.08$ & $1.68 \pm 0.05$ & 2.699 & $0.008 * *$ \\
\hline Woman & $1.59 \pm 0.07$ & $1.58 \pm 0.05$ & 2.640 & $0.006 * *$ \\
\hline $\mathrm{BMI}\left(\mathrm{Kg} / \mathrm{m}^{2}\right)$ & $26.1 \pm 4.30$ & $22.6 \pm 1.95$ & 14.987 & $0.000 * \star *$ \\
\hline BMI type & & & 195.247 & $0.000 * * *$ \\
\hline Under weight & $6(1.4 \%)$ & $2(0.6 \%)$ & & \\
\hline Normal weight & $166(39.0 \%)$ & $291(87.9 \%)$ & & \\
\hline Overweight & $169(39.6 \%)$ & $34(10.3 \%)$ & & \\
\hline Obesity & $85(20.0 \%)$ & $4(1.2 \%)$ & & \\
\hline \multicolumn{5}{|c|}{ Note: ${ }^{*} p<0.05 ; * \star p<0.01 ; * \star \star ~ p<0.001$} \\
\hline
\end{tabular}

\section{Lifestyle and activity levels before fracture}

In general, alcohol consumption in Spanish patients was significantly higher than in Chinese patients, with non-drinkers only $22.8 \%$ in Spain and $66.0 \%$ in China, $p=0.000$. From a gender perspective, Spanish women consume significantly more 
alcohol than Chinese women, but there was no significant difference between men in the two countries, $p=0.000$ and $p=$ 0.295 , respectively. The number of smokers in the Spanish patients was significantly higher than that of the Chinese patients, $p=0.000$. From a gender perspective, the proportion of Chinese women smokers was significantly lower than that of Spanish women, and the difference was statistically significant, $p=0.000$. But there was no difference between male smokers in the two countries, $p=0.276$. The lifestyle of Spanish patients and Chinese patients are shown in Table 2. 
Table 2

Lifestyle of the Spanish and Chinese before the fracture.

\begin{tabular}{|c|c|c|c|c|}
\hline & $\begin{array}{l}\text { Spain } \\
(n=426)\end{array}$ & $\begin{array}{l}\text { China } \\
(n=331)\end{array}$ & test $X^{2}$ & Value $P$ \\
\hline Alcohol consumption & & & 140.913 & $0.000 * * *$ \\
\hline Never & $97(22.8 \%)$ & $215(66.0 \%)$ & & \\
\hline Not in the last year & $155(36.4 \%)$ & $51(15.4 \%)$ & & \\
\hline Less than once a month & $125(29.3 \%)$ & $39(11.8 \%)$ & & \\
\hline Monthly & 37 (8.7\%) & $22(6.7 \%)$ & & \\
\hline Weekly & $10(2.4 \%)$ & $4(1.2 \%)$ & & \\
\hline Daily & $2(0.5 \%)$ & $0(0 \%)$ & & \\
\hline \multicolumn{3}{|c|}{ Alcohol consumption in men } & 6.119 & 0.295 \\
\hline Never & $12(11.2 \%)$ & $11(10.4 \%)$ & & \\
\hline Not in the last year & $28(26.2 \%)$ & 37 (34.9\%) & & \\
\hline Less than once a month & $31(29.0 \%)$ & $33(31.1 \%)$ & & \\
\hline Monthly & $24(22.4 \%)$ & $21(19.8 \%)$ & & \\
\hline Weekly & $10(9.4 \%)$ & $4(3.8 \%)$ & & \\
\hline Daily & $2(1.9 \%)$ & $0(0 \%)$ & & \\
\hline \multicolumn{3}{|c|}{ Alcohol consumption in women } & 217.539 & $0.000 * * *$ \\
\hline Never & $85(26.7 \%)$ & $204(90.7 \%)$ & & \\
\hline Not in the last year & 127 (39.8\%) & $14(6.2 \%)$ & & \\
\hline Less than once a month & $94(29.5 \%)$ & $6(2.7 \%)$ & & \\
\hline Monthly & $13(4.1 \%)$ & $1(0.4 \%)$ & & \\
\hline Weekly & 0 & 0 & & \\
\hline Daily & 0 & 0 & & \\
\hline Smoking & & & 18.739 & $0.000 * \star *$ \\
\hline Does not smoke & 225 (52.8\%) & 225 (68.0\%) & & \\
\hline Active smoker & $55(12.9 \%)$ & $35(10.6 \%)$ & & \\
\hline Former smoker & $146(34.3 \%)$ & $71(21.5 \%)$ & & \\
\hline Smoking in men & & & 2.572 & 0.276 \\
\hline Does not smoke & $11(10.3 \%)$ & 19 (17.9\%) & & \\
\hline Active smoker & $33(30.8 \%)$ & $30(28.3 \%)$ & & \\
\hline Former smoker & $63(58.9 \%)$ & $57(53.8 \%)$ & & \\
\hline Smoking in women & & & 50.815 & $0.000 * * *$ \\
\hline
\end{tabular}

Note: ${ }^{\star} p<0.05 ; * \star p<0.01 ; * \star \star ~ p<0.001$ 


\begin{tabular}{|c|c|c|c|c|}
\hline & $\begin{array}{l}\text { Spain } \\
(n=426)\end{array}$ & $\begin{array}{l}\text { China } \\
(n=331)\end{array}$ & test $X^{2}$ & Value $\mathrm{P}$ \\
\hline Does not smoke & $214(67.1 \%)$ & $209(92.9 \%)$ & & \\
\hline Active smoker & $22(6.9 \%)$ & $3(1.3 \%)$ & & \\
\hline Former smoker & $83(26.0 \%)$ & $13(5.8 \%)$ & & \\
\hline \multicolumn{5}{|c|}{ Note: ${ }^{*} p<0.05 ; * \star p<0.01 ; * \star \star p<<0.001$} \\
\hline
\end{tabular}

\section{Personal medical history}

The common personal medical history of Spanish patients included cardiovascular disease (75.5\%), HT (70.7\%), osteoporosis (59.4\%) and osteoarthritis (54.0\%). On the other hand, those of the Chinese patients were anemia (70.1\%), hypertension (48.9\%) and osteoporosis (45.6\%). Compared with Chinese patients, Spanish patients had a higher proportion of personal history of fracture (30.3\% vs. $23.3 \%)$, personal history of hip fracture (11.3\% vs. $23.3 \%$ ), visual impairment (24.2 $\%$ vs. $10.9 \%)$, HT (70.7\% vs. $48.9 \%)$, DM (35.0\% vs. $21.8 \%)$, cardiovascular disease $(75.5 \%$ vs. $43.0 \%$ ), urinary disease ( $18.3 \%$ vs. $10.3 \%)$, hypothyroidism ( $10.3 \%$ vs. $5.4 \%)$, osteoarthritis ( $54.0 \%$ vs. $45.3 \%)$ and osteoporosis $(59.4 \%$ vs. $45.6 \%)$, the differences were statistically significant, $p=0.031, p=0.010, p=0.000, p=0.000, p=0.000, p=0.002, p=0.015, p=$ 0.018 and $p=0.014$, respectively. However, the incidence of anemia in Chinese patients was higher than that of Spanish patients $(70.1 \%$ vs. $42.3 \%), p=0.000$. There were no significant differences between the patients of two countries in lung, cerebrovascular, gastrointestinal, liver and rheumatoid arthritis disease. Through the previous comparison, we found that the proportion of Spanish patients with multiple pathologies, with more or equal to three, was significantly higher than that of China ( $69.3 \%$ vs. $58.6 \%), p=0.002$. The summary of the comparison of personal medical history between Spain and China is detailed in Table 3. 
Table 3

Comparison of personal medical history between Spain and China

\begin{tabular}{|c|c|c|c|c|}
\hline & $\begin{array}{l}\text { Spain } \\
(n=426)\end{array}$ & $\begin{array}{l}\text { China } \\
(n=331)\end{array}$ & test $X^{2}$ & Value P \\
\hline Personal history of fracture & $129(30.3 \%)$ & $77(23.3 \%)$ & 4.633 & $0.031^{\star}$ \\
\hline Personal history of hip fracture & $47(11.0 \%)$ & $19(5.7 \%)$ & 6.556 & $0.010 * *$ \\
\hline Visual impairment & $103(24.2 \%)$ & $36(10.9 \%)$ & 21.988 & $0.000 * * *$ \\
\hline HT & $301(70.7 \%)$ & $162(48.9 \%)$ & 36.975 & $0.000 * \star \star$ \\
\hline DM & $149(35.0 \%)$ & $72(21.8 \%)$ & 15.759 & $0.000 * \star \star$ \\
\hline Lung disease & $134(31.5 \%)$ & $100(30.2 \%)$ & 0.135 & 0.713 \\
\hline Cardiovascular disease & $326(75.5 \%)$ & $142(43.0 \%)$ & 89.233 & $0.000 * \star \star$ \\
\hline Cerebrovascular disease & $157(36.8 \%)$ & $130(39.3 \%)$ & 0.464 & 0.496 \\
\hline Gastrointestinal disease & $48(11.3 \%)$ & $42(12.7 \%)$ & 0.359 & 0.549 \\
\hline Liver disease & $16(3.8 \%)$ & $15(4.5 \%)$ & 0.285 & 0.593 \\
\hline Urinary disease & $78(18.3 \%)$ & $34(10.3 \%)$ & 9.547 & $0.002^{\star *}$ \\
\hline Anemia & $180(42.3 \%)$ & $232(70.1 \%)$ & 58.199 & $0.000 * \star \star$ \\
\hline Hypothyroidism & $44(10.3 \%)$ & $18(5.4 \%)$ & 5.925 & $0.015^{\star}$ \\
\hline Osteoarthritis & $230(54.0 \%)$ & $150(45.3 \%)$ & 5.605 & $0.018^{*}$ \\
\hline Rheumatoid arthritis & $82(19.3 \%)$ & $60(18.1 \%)$ & 0.154 & 0.695 \\
\hline Osteoporosis & $253(59.4 \%)$ & $151(45.6 \%)$ & 6.050 & $0.014^{\star}$ \\
\hline Pluripathology & & & 9.218 & $0.002 * \star$ \\
\hline$<3$ & $131(30.8 \%)$ & $137(41.4 \%)$ & & \\
\hline$\geq 3$ & $295(69.3 \%)$ & $194(58.6 \%)$ & & \\
\hline
\end{tabular}

\section{Characteristics related to injury, anesthesia and surgery}

As shown in Table 4, more than half of the falls in Spain occurred outside the home (51.2\%), while most of the falls in Chinese patients occurred within the home $(61.3 \%), p=0.001$. Furthermore, most of the falls occurred mainly during the day, but the proportion of patients in Spain was higher than in China (76.8\% vs. $68.9 \%), p=0.015 .59 .5 \%$ of Chinese patients had moderate and normal mobility, which was higher than $49.5 \%$ of Spanish patients, indicating that Chinese patients had better mobility before fracture, $p=0.036$. When analyzing the causes of falls, we found that falls when walking predominate in both countries, but the proportion from China was higher than that of Spain $(66.8 \%$ vs. $61.7 \%), p=0.031$. There was no significant difference in the comparison of the type and side of the fracture between the two countries, $p=0.162$ and $p=$ 0.085 , respectively. In terms of anesthesia, $96.7 \%$ of patients in Spain used regional anesthesia, while in China, $91.8 \%$ of patients received general anesthesia, $p=0.000$. According to the American Society of Anesthesiologists (ASA) classification, the proportion of high-risk patients with anesthesia in Spain was significantly higher than that in China (83.1\% vs. $60.1 \%), p$ $=0.000$. The operation delay time of Spanish patients was significantly longer than that of Chinese patients $(78.7 \pm 48.2$ vs. $60.7 \pm 43.1$ hours), $p=0.000$. In addition, all Spanish patients (100\%) underwent surgery on weekdays, while $14.8 \%$ of 
Chinese patients underwent surgery on weekends, $p=0.000$. At the same time, $49.3 \%$ of Spanish patients needed to pass the weekend to undergo surgery, while only $18.7 \%$ in China, $p=0.000$. In the comparison of surgical methods, 216 (50.7\%) patients in Spain received osteosynthesis and 210 (49.3\%) received prosthetic treatment; in China, there were 126 (38.7\%) and $203(61.3 \%), p=0.001$. Specific to the choice of surgical methods for different types of fractures, of the 215 cases of femoral neck fractures in Spain, 210 cases $(97.7 \%)$ received prosthetic treatment, and 5 cases $(2.3 \%)$ received osteosynthesis; while 184 cases of femoral neck fractures in China, 172 cases (93.1\%) and 12 cases (6.9\%) were treated with prosthesis and osteosynthesis, respectively, $p=0.039$. Among patients with intertrochanteric fractures, all $211 \mathrm{Spanish}$ patients underwent osteosynthesis; however, of the 147 patients with intertrochanteric fractures in China, 116 (78.9\%) received osteosynthesis and $31(21.1 \%)$ received prosthetic treatment, $p=0.000$. Regarding the operation time, no difference was observed between the two countries, $p=0.671$. Whether before or after surgery, the average hemoglobin level of Spanish patients was higher than that of Chinese patients ( $12.0 \pm 1.8$ vs. $11.4 \pm 1.3$ and $9.4 \pm 1.3$ vs. $9,2 \pm 0.5), p=0.000$ and $p=0.000$, respectively. Therefore, more Chinese patients received blood transfusion, $139(42.0 \%)$ vs. $138(30.1 \%), p=$ 0.007 . 
Table 4

Characteristics related to injury, anesthesia and surgery of patients between spain and china

\begin{tabular}{|c|c|c|c|c|}
\hline & $\begin{array}{l}\text { Spain } \\
(n=426)\end{array}$ & $\begin{array}{l}\text { China } \\
(n=331)\end{array}$ & test $t / X^{2}$ & Value $\mathrm{P}$ \\
\hline Falling place & & & 11.734 & $0.001^{* * *}$ \\
\hline At home & $208(48.8 \%)$ & $203(61.3 \%)$ & & \\
\hline Outdoors & $218(51.2 \%)$ & $128(38.7 \%)$ & & \\
\hline Fall time & & & 5.910 & $0.015^{\star}$ \\
\hline Day & $327(76.8 \%)$ & $228(68.9 \%)$ & & \\
\hline Night & $99(23.2 \%)$ & $103(31.1 \%)$ & & \\
\hline Activity level before the fracture & & & 4.394 & $0.036^{*}$ \\
\hline Bedridden & $4(0.9 \%)$ & $4(1.2 \%)$ & & \\
\hline Decreasing & $211(49.5 \%)$ & $130(39.3 \%)$ & & \\
\hline Moderately & $144(33.8 \%)$ & $138(41.7 \%)$ & & \\
\hline Normal & $67(15.7 \%)$ & $59(17.8 \%)$ & & \\
\hline Causes of falling & & & 10.671 & $0.031^{*}$ \\
\hline Knocked down & $33(7.8 \%)$ & $23(7.0 \%)$ & & \\
\hline Get up or sit down & $42(9.9 \%)$ & $44(13.3 \%)$ & & \\
\hline Go to the toilet or bathe & $60(14.1 \%)$ & $34(10.3 \%)$ & & \\
\hline Falls while walking & $263(61.7 \%)$ & $221(66.8 \%)$ & & \\
\hline Others & $28(6.6 \%)$ & $9(2.7 \%)$ & & \\
\hline Type of fracture & & & 1.959 & 0.162 \\
\hline Femoral neck & $215(50.5 \%)$ & $184(55.6 \%)$ & & \\
\hline Intertrochanteric & $211(49.5 \%)$ & $147(44.4 \%)$ & & \\
\hline Fracture side & & & 2.974 & 0.085 \\
\hline Left & $219(51.4 \%)$ & $191(57.7 \%)$ & & \\
\hline Right & $207(48.6 \%)$ & $140(42.3 \%)$ & & \\
\hline Anesthesia mode & & & 599.629 & $0.000 * * *$ \\
\hline General & $14(3.3 \%)$ & 304 (91.8\%) & & \\
\hline Regional & $412(96.7 \%)$ & $27(8.2 \%)$ & & \\
\hline ASA grade & & & 65.976 & $0.000 * \star \star *$ \\
\hline Grade I & $2(0.5 \%)$ & $31(9.4 \%)$ & & \\
\hline Grade II & $68(16.0 \%)$ & $101(30.5 \%)$ & & \\
\hline
\end{tabular}




\begin{tabular}{|c|c|c|c|c|}
\hline & $\begin{array}{l}\text { Spain } \\
(n=426)\end{array}$ & $\begin{array}{l}\text { China } \\
(n=331)\end{array}$ & test $t / X^{2}$ & Value $\mathrm{P}$ \\
\hline Grade III & $297(69.7 \%)$ & $161(48.6 \%)$ & & \\
\hline Grade IV & $59(13.9 \%)$ & $38(11.5 \%)$ & & \\
\hline ASA risk & & & 49.957 & $0.000 * \star \star$ \\
\hline Low & $72(16.9 \%)$ & $132(39.9 \%)$ & & \\
\hline High & $354(83.1 \%)$ & $199(60.1 \%)$ & & \\
\hline Waiting time for surgery (h) & $78.7 \pm 48.2$ & $60.7 \pm 43.1$ & 5.355 & $0.000 * * *$ \\
\hline Surgical delay time & & & 12.535 & $0.000 * * *$ \\
\hline Early ( $\leq 48$ hours) & $154(36.2 \%)$ & $162(48.9 \%)$ & & \\
\hline Late (> 48 hours) & $272(63.9 \%)$ & $169(51.1 \%)$ & & \\
\hline Surgical date & & & 67.428 & $0.000 * * *$ \\
\hline Weekdays & $426(100 \%)$ & $282(85.2 \%)$ & & \\
\hline Weekends & $0(0 \%)$ & $49(14.8 \%)$ & & \\
\hline Pass the weekend to surgery & $210(49.3 \%)$ & $62(18.7 \%)$ & 75.590 & $0.000 * * *$ \\
\hline Surgical methods & & & 10.880 & $0.001^{* * *}$ \\
\hline Osteosynthesis & $216(50.7 \%)$ & $128(38.7 \%)$ & & \\
\hline Prosthesis & $210(49.3 \%)$ & $203(61.3 \%)$ & & \\
\hline Surgical methods for femoral neck & fracture & & 4.280 & $0.039 *$ \\
\hline Osteosynthesis & $5(2.3 \%)$ & $12(6.9 \%)$ & & \\
\hline Prosthesis & $210(97.7 \%)$ & $172(93.1 \%)$ & & \\
\hline Surgical methods for intertrochant & ric fracture & & 48.715 & $0.000 * \star \star$ \\
\hline Osteosynthesis & $211(100 \%)$ & $116(78.9 \%)$ & & \\
\hline Prosthesis & $0(0 \%)$ & $31(21.1 \%)$ & & \\
\hline Surgical time (minutes) & $70.0 \pm 15.8$ & $70.4 \pm 13.1$ & 0.425 & 0.671 \\
\hline Preoperative hemoglobin (g/dL) & $12.0 \pm 1.8$ & $11.4 \pm 1.3$ & 5.737 & 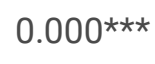 \\
\hline Postoperative hemoglobin (g/dL) & $9.4 \pm 1.3$ & $9.2 \pm 0.5$ & 3.559 & $0.000 * * *$ \\
\hline Blood transfusion & $138(30.1 \%)$ & $139(42.0 \%)$ & 7.398 & $0.007 * \star$ \\
\hline \multicolumn{5}{|c|}{ Note: * $p<0.05 ; * \star p<0.01 ; * \star * p<0.001$} \\
\hline
\end{tabular}

\section{Days and costs of hospitalization, and time of bed rest}

Compared with Chinese patients, Spanish patients had a shorter hospital stay ( $9.2 \pm 5.3$ vs. $12.9 \pm 3.3$ days), but the time of bed rest was longer in Spanish ( $20.0 \pm 5.3$ vs. $16.2 \pm 8.2$ days), $p=0.000$ and $p=0.005$, respectively. Furthermore, the time of bed rest with osteosynthesis was significantly longer than that with prosthesis ( $29.9 \pm 19.3 \mathrm{vs}$. $8.7 \pm 8.9$ days $), p=0.000$. The average cost was 13,179 $\pm 1,496$ and 5,851 \pm 686 euros in Spain and China, respectively, $p=0.000$.(Table 5) 
Table 5

Days and costs of hospitalization, and time of bed rest between Spain and China

\begin{tabular}{|c|c|c|c|c|}
\hline & $\begin{array}{l}\text { Spain } \\
(n=426)\end{array}$ & $\begin{array}{l}\text { China } \\
(n=331)\end{array}$ & test $\mathrm{t}$ & Value $\mathrm{P}$ \\
\hline Hospital stay (days) & $9.2 \pm 5.3$ & $12.9 \pm 3.3$ & 8.592 & $0.000 * \star *$ \\
\hline Time of bed rest (days) & $20.0 \pm 5.3$ & $16.2 \pm 8.2$ & 2.831 & $0.005^{\star \star}$ \\
\hline \multirow[t]{2}{*}{ Cost of hospitalization (euros) } & $13.179 \pm 1496$ & $5.851 \pm 686$ & 256.934 & $0.000 * * *$ \\
\hline & Osteosynthesis & Prosthesis & test $t$ & Value $P$ \\
\hline Time of bed rest (days) & $29.9 \pm 19.3$ & $8.7 \pm 8.9$ & 18.379 & $0.000 * *$ \\
\hline
\end{tabular}

\section{Harris hip score and mortality}

In the comparison of the Harris hip score, the excellent and good rates for Spanish and Chinese patients were $84.7 \%$ and $88.6 \%, p=0.484$. During the one-year follow-up, 81 cases $(19.01 \%)$ died in Spain and 43 cases (12.99\%) died in China, $p=$ 0.026. Among Chinese patients with intertrochanteric fractures, 31 patients who received prostheses had a one-year mortality rate of $12.9 \%$, while the remaining 116 patients who received osteosynthesis had a mortality rate of $22.4 \%$. (Table 6)

Table 6

Harris hip score and mortality between Spain and China

\begin{tabular}{|c|c|c|c|c|}
\hline & $\begin{array}{l}\text { Spain } \\
(n=426)\end{array}$ & $\begin{array}{l}\text { China } \\
(n=331)\end{array}$ & test t & Value P \\
\hline \multicolumn{3}{|l|}{ Harris hip score } & 2.454 & 0.484 \\
\hline Excellent & $159(39.3 \%)$ & $131(40.3 \%)$ & & \\
\hline Good & $184(45.4 \%)$ & $157(48.3 \%)$ & & \\
\hline Regular & $48(11.9 \%)$ & $28(8.6 \%)$ & & \\
\hline Bad & $14(3.5 \%)$ & $9(2.8 \%)$ & & \\
\hline Mortality within one year & $81(19.01 \%)$ & $43(12.99 \%)$ & 4.934 & $0.026^{*}$ \\
\hline \multicolumn{5}{|c|}{ Note: * $p<0.05 ;{ }^{* *} p<0.01 ; * \star * p<0.001$} \\
\hline
\end{tabular}

\section{Discussions}

This article is the first study to compare the status quo of hip fractures in Spain and China. By collecting clinical information on hip fracture patients treated in two large hospitals, we found that the epidemiology of hip fractures vary due to the differences in the economy, medical level, and cultural concepts of the two countries.

In our study, the basic demographic data of the population showed a pattern similar to the known characteristics of hip fractures around the world, with most hip fracture patients over 65 years of age. Among all these people, women, especially Spanish women, have a higher proportion of hip fractures, accounting for about three-quarters, while Chinese women 
account for about two-thirds. This is consistent with the results of other reports $[8,15]$. Secondly, we see that the average age of Spanish patients is significantly higher than that of China. The possible reason is the difference in average life expectancy. In 2019, the average life expectancy of the Spanish was 82.8 years, while that of the Chinese was 76.1 years[16]. Regarding anthropometric characteristics, the height, weight and BMI of Spanish patients are significantly higher than those of Chinese patients. The first reason is genetic: the average height of Europeans is higher than that of East Asians. Another reason may be that the birth and development of Chinese patients in this age group was in a period of war and poverty, resulting in their height and weight lower than Spanish patients. On the other hand, regarding overweight and obesity rates, Spanish patients are significantly higher than Chinese patients, especially women. According to reports, as the living conditions of Chinese people continue to improve, the proportion of overweight and obese hip fracture patients in China will gradually increase in the coming decades[17]. A meta-analysis found that there is a correlation between BMI and bone mass, that is, the higher the BMI, the better the bone density, which is considered to be a protective factor for osteoporotic hip fractures, and put forward the viewpoint of increasing the BMI of the elderly to reduce the incidence of hip fractures[18]. However, from the study we conducted, the percentage of overweight and obese patients with hip fractures in Spain is close to $60 \%$, which is significantly higher than the percentage in the normal population[19]. Perhaps this is because obese patients do not have much flexibility, are more likely to fall, and the excessive weight at the time of injury exerts more force, which offsets the better bone density[20,21]. In addition, it is well known that obesity is also a risk factor for many diseases, such as cardiovascular and cerebrovascular diseases, diabetes, and arthritis[22]. Moreover, the BMI level is negatively correlated with the postoperative rehabilitation effect of hip fractures, that is, the higher the BMI, the worse the postoperative functional rehabilitation[23]. For these reasons, we suggest that maintaining a normal BMI is the healthiest option, rather than increasing BMI to reduce the incidence of hip fractures.

Many studies have shown that alcohol affects bone metabolism, not only inhibits bone synthesis, but also increases bone resorption through direct and indirect pathways, leading to osteopenia and osteoporosis, thereby increasing the risk of fractures[24, 25]. In our comparative study, we found that the proportion of Spanish women drinking is significantly higher than that of Chinese women. According to a survey conducted by the Spanish National Statistics Office, only $11.5 \%$ of men and $29.2 \%$ of women have never drunk alcohol[26]. These data are similar to our research. And the proportion of habitual drinking continues to increase, especially among Spanish women[26]. As we all know, China is a country with massive alcohol intake. However, because of the culture and different occupations they hold, the number of Chinese women who drink is very small, especially among those born before 1980. To be sure, as social patterns and activities change in this country, this proportion of Chinese women who drink will gradually increase[27]. Indeed, the diversification of the culture and the diverse occupations to which women are joining will make a greater number of them consume alcohol in a greater proportion in the coming year[28]. As for smoking, low bone density is one of its negative impacts. And smoking is associated with increased fracture risk in men and women and delayed fracture healing[29]. Research by Dimitris showed that compared with never-smokers, ex-smokers or active smokers have an increased risk of hip fractures, but the longer they quit smoking, the lower the risk of fractures. Our research shows that the proportion of smokers among Spanish patients is significantly higher than that of Chinese patients, which is mainly due to the difference in tobacco consumption among women in these two countries. Like drinking, with the openness of perceptions and the diversification of occupations, the proportion of Chinese women who smoke is also slowly rising, especially in cities[30]. Therefore, the higher consumption of tobacco and alcohol by Spanish women may be one of the reasons why they account for a higher proportion of hip fractures than Chinese women.

Hip fracture patients over 65 years of age often have multiple personal medical histories. The internal homeostasis of the patient is altered by the hip fracture, which causes a continuous deterioration of his general condition. It is noteworthy to note that $75 \%$ of patients do not die due to the pathology of the hip fracture itself, but rather as a consequence of a comorbidity prior to the injury[31]. Yoon et al. have shown that dementia and DM have a significant effect on postoperative functional outcomes[32]. Anemia will increase hospital complications as well as hospitalization costs[33]. A meta-analysis shows that malignant tumors, lung disease, DM, and cardiovascular disease significantly increase the risk of death after hip fracture surgery[34]. Studies have shown that personal history of fracture is one of the major risk factors for hip

Page $13 / 20$ 
fractures[35]. A survey of hip fractures carried out in 45 Spanish hospitals showed that $36.5 \%$ of patients have personal history of fracture, with $10.2 \%$ of them having personal history of hip fracture[36]. This result is similar to the result of the Spanish sample in our study. In addition, some studies have shown that having more than 3 common comorbidities are risk factors that lead to the death of patients in one year[37]. In this study, we have found that the proportion of patients with 3 or more types of comorbidities is significantly higher in Spain than in China. This especially happens in relation to visual problems, DM, HT, cardiovascular diseases, personal history of fracture, osteoporosis, etc., which may be one of the reasons why the mortality rate of Spanish patients is higher, comparatively with Chinese. In summary, the comorbidities of elderly patients with hip fractures are not only related to the increased risk of osteoporosis and falls, but also to the increased risk of postoperative hip fracture death. Therefore, active prevention and treatment of elderly comorbidities can reduce the incidence and mortality of hip fractures.

Falls are the main cause of hip fractures, which have important psychological consequences in patients, such as the fear of them, from that moment on, and the loss of self-confidence. These reasons can affect self-restricted activity, reduced physical function, and social interactions, which normally place great pressure on the family. Among the most common causes of falls, the highest incidence is when walking. After that, when getting up or sitting down, and falling in the bathroom. Prevention measures, therefore, should include: exercise, particularly balance, strength, and gait training; take vitamin D supplements with or without calcium; take medications, especially psychoactive ones; modifying the home environment, such as improving lighting or installing handrails in bathrooms; and attend to postural hypotension, vision, foot and shoe problems. Acting according to these aspects causes an effective reduction in falls, both in private homes and in nursing homes[38]. In addition, we also found an interesting phenomenon: although the pre-fracture activity of Spanish patients is worse than that of Chinese patients (50.4\% in Spain have no activity or little activity, and $40.3 \%$ in China), but more Spanish patients fell during the day and outside. We think this is because Spain has better public auxiliary transportation facilities, which makes it more convenient for elderly people with mobility impairments. For example, in Seville, there are lanes dedicated to wheelchairs on both sides of the street; there are no steps on the bus, and it is more convenient for the elderly on crutches to get on and off the bus, and there is a ramp for wheelchairs on the bus. Another reason may be that older people in Spain have a more open perception and are more willing to enjoy a free and better life outdoors. In contrast, in Xi'an, China, the details of public transportation facilities are not friendly enough. For example, there are steps for getting on and off the bus, which is inconvenient for the elderly. In contrast, in Xi'an, China, the details of public transportation facilities are not friendly enough. For example, there are steps for getting on and off the bus, which is inconvenient for the elderly. In addition, in China, due to the conservative and traditional perception, more elderly people spend their time on the sofa watching TV or on the rocking chair on the balcony. All of this explains the interesting results we got in this study.

The main method of treatment for elderly hip fracture patients is surgery, which can significantly reduce the mortality rate and achieve the benefits of treatment. In our study, there are significant differences in the choice of surgical methods for patients between the two countries. In femoral neck fractures, although most patients in both countries have received more prosthetic treatment, 12 cases of fractures in China have received osteosynthesis, while only 5 cases in Spain. The main reason is that these Chinese patients are relatively younger, and osteosynthesis with femoral head preservation is the preferred treatment[39]. However, for intertrochanteric fractures, all Spanish patients received osteosynthesis, while 31 Chinese patients received prostheses. Studies have shown that the use of prosthesis for the treatment of unstable intertrochanteric fractures is significantly better than internal fixation in terms of walking time, postoperative complications, Harris hip score and mortality[40]. Among Chinese patients with intertrochanteric fractures, 31 patients who received prostheses had a one-year mortality rate of $12.9 \%$, while the remaining 116 patients who received osteosynthesis had a mortality rate of $22.4 \%$. This indicates that the prosthesis is a good therapeutic alternative for unstable intertrochanteric fractures. Therefore, Spanish orthopedic surgeons should also consider the choice of prosthesis for intertrochanteric fractures.

Page $14 / 20$ 
We also found that Spanish patients had longer surgery delays than Chinese patients. This is because there are many patients in Spain waiting for surgery on weekends, while $14.8 \%$ of Chinese patients have surgery on weekends. The main reason for this difference is the healthcare system and the medical environment. In fact, in Spain, except for emergencies, they only perform operations on working days, while in China, they are also undergoing intensive operations on Saturdays. In the medical environment, Chinese patients and their families are more rude to medical staff and even more aggressive, so they require doctors to sacrifice their time to perform operations as soon as possible[41]. A number of studies have shown that surgical delay is an independent risk factor for postoperative death in patients with hip fractures, and early surgery can reduce perioperative complications and mortality $[42,43]$. Some scholars also believe that optimizing diagnosis and treatment channels can reduce the waiting time before surgery and improve the prognosis of patients[44]. This may also be a reason for the higher mortality rate among Spanish patients.

In terms of anesthesia, XDH in China prefers general anesthesia, while UHVM in Spain most commonly uses regional anesthesia. This difference only appeared in the two hospitals evaluated, and it does not represent the two countries. In fact, according to our review of Chinese literature[45], many Chinese hospitals use more regional anesthesia than general anesthesia. However, more research evidence shows that different anesthesia methods will not affect the complications and mortality of patients with hip fractures[46]. In the comparison of ASA classification, the high-risk ratio of Spanish patients is significantly higher than that of Chinese patients, indicating that the overall condition of Spanish patients is worse. The Wang's study shows that the high risk of ASA is an independent risk factor for death from hip fracture within one year[47]. This may be one of the reasons why the mortality rate of Spanish patients is higher than that of Chinese patients. In our study, there are more Chinese elderly people suffering from anemia, and the preoperative hemoglobin is significantly lower than that of the Spanish. Studies have shown that the higher the BMI, the lower the possibility of anemia[33], which may be the reason why the elderly in China are more likely to suffer from anemia. Therefore, more Chinese patients have to receive blood transfusions.

Compared with other closed fractures, patients with hip fractures have longer hospital stays because of more comorbidities, longer surgical delays, and other postoperative complications[48]. In this study, the average hospital stay of Chinese patients is longer than that of Spanish patients. The main reason is that many Chinese patients do not have clinics or hospitals near their homes, making it difficult to change dressings and remove sutures from wounds after surgery. However, a longer hospital stay may be beneficial to the patient. A national cohort study in Sweden showed that a hospital stay of less than 10 days, each day less spent in hospital, had an $8 \%$ increase in the probability of death within 30 postoperative day. Conversely, when the hospital stay was more than 11 days, the decrease in the hospital stay of one day was not associated with an increased risk of death after discharge[49]. Similarly, a South Korean study found that elderly patients with hip fractures who were hospitalized for less than 10 days had a higher mortality rate within one year after discharge[50]. Reducing the length of hospital stay means shortening the time for patients to receive nursing care in the hospital after the operation, as well as shortening the time for comprehensive assessment of the medical condition during this period. However, this comprehensive geriatric assessment has the advantage of being able to reduce the risk of complications after hip fracture, as well as death after discharge[49,51]. Therefore, it is recommended that the discharge time for patients with hip fracture be done once the wound sutures have been removed. We consider it important for two reasons: first, that patients and their families can learn more necessary knowledge of nursing, as well as rehabilitation; The second reason is that after removing the sutures, patients no longer have to worry about the wound and can perform rehabilitation exercises more assured and bolder.

In fact, the length of time in bed is closely related to the patient's prognosis. The incidence of pressure ulcers, pulmonary infections, venous thrombosis, muscle atrophy, and cardiovascular complications increases with time spent in bed[52]. In this study, the average number of days of bed rest for Chinese patients was significantly lower than that of Spanish patients, and the bed rest time of prosthesis treatment was significantly shorter than that of osteosynthesis treatment. In this study, the average number of days of bed rest for Chinese patients was significantly lower than that of Spanish patients, and the bed rest time for prosthetic treatment was significantly shorter than that for osteosynthesis treatment.

Page $15 / 20$ 
Because Chinese patients are relatively young, have better abilities before injury, and have received more rehabilitation exercises and nursing knowledge guidance during their hospitalization, there are even 31 patients with femoral intertrochanteric fractures who have received prosthetic treatment. These favorable reasons enable them to return to underground activities faster after the operation.

Regarding hospitalization costs, Spanish patients are significantly higher than Chinese patients. However, due to differences in price levels and purchasing power, we must compare them in another way. We believe that in this case, the average wage is a good method. For example, the average annual income of residents of Seville in 2019 was 16,271 euros[53], while in Xi'an it was 58,080 RMB, approximately 7,260 euros[54]. In other words, the hospitalization costs for hip fractures in the two countries are relatively similar, about 10 months' salary. Finally, we must point out that as the elderly population increases, prevention has become the best strategy to reduce the cost of hip fractures, thereby reducing the high costs borne by the health system and families.

Hip fracture is called the last fracture in life due to the high mortality and disability rate. The one-year mortality rate after a hip fracture is $15-40 \%$, which is 3 to 4 times higher than the general population $[55,56]$. In this study we have seen one-year mortality rates of $19.01 \%$ in Spain and $12.99 \%$ in China. A recent meta-analysis carried out in China showed that the oneyear mortality rate was $13.96 \%[14]$. In Spain, a study using national data showed that the annual mortality rate for men and women under 80 years of age is $22 \%$; that of women over this age was $25.2 \%$, while that of men was $30.1 \%$ [57]. Based on these data, we can conclude that the one-year mortality rate of hip fracture patients in China is lower than that of Spain. However, in terms of postoperative functional recovery, the results of both countries are satisfactory, and the excellent and good rate of Harris score has reached a high level.

This is the first study to compare the epidemiology and mortality of hip fractures in Spain and China. This study has the following advantages. First, the two selected hospitals, UHVM in Seville and XDH in Xi'an, are large-scale comprehensive tertiary hospitals and are typical representatives of hospitals in the two countries. Secondly, the sample size is large, with a total of 757 patients included. In addition, the study includes a wide range of variables, such as pre-injury status, lifestyle and comorbidities, and the content of the comparison is very detailed. However, some limitations have affected the research: First, each hospital has its own culture and environment, and the data may not be representative of other hospitals in the two countries, such as anesthesia methods. Another important limitation of this study is related to the follow-up method. Especially for Chinese patients, because the electronic medical record systems between hospitals are not connected to the Internet, we cannot obtain information about patients going to other hospitals after they are discharged. Therefore, for some of the Chinese patients, their death information was obtained by calling their family members, which may lead to the loss of some important information related to the death. In addition, the risk factors that affect the death of patients are an important research topic, but they were not carried out in this study.

\section{Conclusion}

In summary, our research shows that there are large epidemiological differences between hip fracture patients in Seville, Spain and Xi'an, China. Among them, differences in gender, age, injury location, comorbidities, etc. cannot be changed by admonishing patients or choosing treatment methods. However, we can narrow the difference by advising patients to maintain a normal BMI, develop a good lifestyle, and choosing appropriate surgical methods to provide patients with a better foundation for rehabilitation and reduce mortality.

\section{List Of Abbreviations}

ASA

American Society of Anesthesiologists

BMI

Body Mass Index 
DM

Diabetes mellitus

HT

Hypertension

UHVM

University Hospital Virgen Macarena

$\mathrm{XDH}$

Xi'an Daxing Hospital

\section{Declarations}

Ethics approval and consent to participate: This study passed the review of the ethics committees of Xi'an Daxing Hospital in China and Hospital Universitario Virgen Macarena in Seville, Spain. This study is a retrospective study and does not involve the personal information of the patients, so there is no need to sign the patient's informed consent. The opinions of the ethics committee can be found in the supplementary materials.

Consent for publication: Not applicable

Availability of data and materials: The datasets used and/or analysed during the current study are available from the corresponding author on reasonable request.

Competing interests: The authors declare that they have no competing interests

Funding: No

Authors' contributions: Shuai-Shuai Gao and Wen-Tting Zhang conceived, designed and wrote the article; Yan-Jun Wang, Yong-Feng Yao, Ya-Hui Zhang and Aurelio Borrás Verdera conducted data collection and analysis. Luis C CapitanMorales revised and corrected the article. All authors reviewed the final manuscript. All authors agree to be accountable for all aspects of the work.

Acknowledgements: Not applicable

\section{References}

1. Rashki Kemmak A, Rezapour A, Jahangiri R, Nikjoo S, Farabi H, Soleimanpour S. Economic burden of osteoporosis in the world: A systematic review. Med J Islam Repub Iran. 2020;34(154-154. https://doi.org/10.34171/mjiri.34.154

2. Cooper C, Campion G, Melton LJ, 3rd. Hip fractures in the elderly: a world-wide projection. Osteoporos Int. 1992;2(6):285-289. https://doi.org/10.1007/bf01623184

3. Rapp K, Büchele G, Dreinhöfer K, Bücking B, Becker C, Benzinger P. Epidemiology of hip fractures. Zeitschrift für Gerontologie und Geriatrie. 2019;52(1):10-16. https://doi.org/10.1007/s00391-018-1382-z

4. Moon RJ, Harvey NC. Identification of patient profile for treatment. Best Practice \& Research Clinical Endocrinology \& Metabolism. 2014;28(6):767-782. https://doi.org/10.1016/j.beem.2014.04.005

5. Population structure Indicators. Available from: https://www.ine.es/jaxiT3/Tabla.htm?t=1488.

6. Serra JA, Garrido G, Vidán M, Marañón E, Brañas F, Ortiz J. [Epidemiology of hip fractures in the elderly in Spain]. Anales de medicina interna (Madrid, Spain: 1984). 2002;19(8):389-395.

7. Herrera A, Martínez AA, Ferrandez L, Gil E, Moreno A. Epidemiology of osteoporotic hip fractures in Spain. Int Orthop. 2006;30(1):11-14. https://doi.org/10.1007/s00264-005-0026-2 
8. Guzon-Illescas O, Perez Fernandez E, Crespí Villarias N, et al. Mortality after osteoporotic hip fracture: incidence, trends, and associated factors. Journal of orthopaedic surgery and research. 2019;14(1):203. https://doi.org/10.1186/s13018019-1226-6

9. Aguilar del Rey FJ, Pérez González O. Epidemiology of osteoporotic fractures in Andalusia, Spain, from 2000-2010. Medicina Clínica (English Edition). 2018;150(8):297-302. https://doi.org/10.1016/j.medcle.2018.02.004

10. Rey-Rodriguez MM, Vazquez-Gamez MA, Giner M, et al. Incidence, morbidity and mortality of hip fractures over a period of 20 years in a health area of Southern Spain. BMJ open. 2020;10(9):e037101. https://doi.org/10.1136/bmjopen2020-037101

11. Caeiro JR, Bartra A, Mesa-Ramos M, et al. Burden of First Osteoporotic Hip Fracture in Spain: A Prospective, 12-Month, Observational Study. Calcified tissue international. 2017;100(1):29-39. https://doi.org/10.1007/s00223-016-0193-8

12. Zhang C, Feng J, Wang S, et al. Incidence of and trends in hip fracture among adults in urban China: A nationwide retrospective cohort study. PLoS Med. 2020;17(8):e1003180-e1003180. https://doi.org/10.1371/journal.pmed.1003180

13. Gong XF, Li XP, Zhang LX, et al. Current status and distribution of hip fractures among older adults in China. Osteoporos Int. 2021;https://doi.org/10.1007/s00198-021-05849-y

14. Cui Z, Feng H, Meng X, et al. Age-specific 1-year mortality rates after hip fracture based on the populations in mainland China between the years 2000 and 2018: a systematic analysis. Archives of osteoporosis. 2019;14(1):55-55. https://doi.org/10.1007/s11657-019-0604-3

15. Zhu Y, Xing X, Liu S, Chen W, Zhang X, Zhang Y. Epidemiology of low-energy wrist, hip, and spine fractures in Chinese populations 50 years or older: A national population-based survey. Medicine. 2020;99(5):e18531-e18531. https://doi.org/10.1097/MD.0000000000018531

16. World Health O. World health statistics 2019: monitoring health for the SDGs, sustainable development goals. Geneva: World Health Organization; 2019.

17. Ma S, Xi B, Yang L, Sun J, Zhao M, Bovet P. Trends in the prevalence of overweight, obesity, and abdominal obesity among Chinese adults between 1993 and 2015. International journal of obesity (2005). 2021;45(2):427-437. https://doi.org/10.1038/s41366-020-00698-x

18. Johansson $\mathrm{H}$, Kanis JA, Odén A, et al. A meta-analysis of the association of fracture risk and body mass index in women. Journal of bone and mineral research: the official journal of the American Society for Bone and Mineral Research. 2014;29(1):223-233. https://doi.org/10.1002/jbmr.2017

19. Rodríguez-Rodríguez E, López-Plaza B, López-Sobaler AM, Ortega RM. Prevalencia de sobrepeso y obesidad en adultos españoles. Nutrición Hospitalaria. 2011;26(355-363.

20. Mitchell RJ, Lord SR, Harvey LA, Close JC. Associations between obesity and overweight and fall risk, health status and quality of life in older people. Australian and New Zealand journal of public health. 2014;38(1):13-18. https://doi.org/10.1111/1753-6405.12152

21. S GRN, J SO, A BD, R ML, Tiedemann A. Does Obesity Increase the Risk and Severity of Falls in People Aged 60 Years and Older? A Systematic Review and Meta-analysis of Observational Studies. J Gerontol A Biol Sci Med Sci. 2020;75(5):952-960. https://doi.org/10.1093/gerona/glz272

22. Upadhyay J, Farr O, Perakakis N, Ghaly W, Mantzoros C. Obesity as a Disease. Med Clin North Am. 2018;102(1):13-33. https://doi.org/10.1016/j.mcna.2017.08.004

23. Akinleye SD, Garofolo G, Culbertson MD, Homel P, Erez O. The role of BMI in hip fracture surgery. Geriatric orthopaedic surgery \& rehabilitation. 2018;9(2151458517747414.

24. Luo Z, Liu Y, Liu Y, Chen H, Shi S, Liu Y. Cellular and molecular mechanisms of alcohol-induced osteopenia. Cellular and Molecular Life Sciences. 2017;74(24):4443-4453. https://doi.org/10.1007/s00018-017-2585-y

25. Fung TT, Mukamal KJ, Rimm EB, Meyer HE, Willett WC, Feskanich D. Alcohol intake, specific alcoholic beverages, and risk of hip fractures in postmenopausal women and men age 50 and older. Am J Clin Nutr. 2019;110(3):691-700.

Page $18 / 20$ 
https://doi.org/10.1093/ajcn/nqz135

26. INE. Determinantes de salud (consumo de tabaco, exposición pasiva al humo de tabaco, alcohol, problemas medioambientales en la vivienda). Available from: https://www.ine.es/ss/Satellite?

L=es_ES\&C=INESeccion_C\&cid=1259926698156\&p=1254735110672\&pagename=ProductosYServicios\%2FPYSLayout.

27. Fang Yuehui, He Yuna, Bai Guoyin, Zhao Wenhua. Prevalence of alcohol drinking and influencing factors in female adults in China, 2010-2012. Chinese Journal of Epidemiology, 2018, 39(11): 1432-1437.

28. Thibaut F. Alert out on tobacco and alcohol consumption in young European women. European Archives of Psychiatry and Clinical Neuroscience. 2018;268(4):317-319. https://doi.org/10.1007/s00406-018-0901-7

29. Al-Bashaireh AM, Haddad LG, Weaver M, Kelly DL, Chengguo X, Yoon S. The Effect of Tobacco Smoking on Musculoskeletal Health: A Systematic Review. Journal of Environmental and Public Health. 2018;2018(4184190. https://doi.org/10.1155/2018/4184190

30. Parascandola M, Xiao L. Tobacco and the lung cancer epidemic in China. Transl Lung Cancer Res. 2019;8(Suppl 1):S21-S30. https://doi.org/10.21037/tlcr.2019.03.12

31. Liu Z, Zhang J, He K, Zhang Y, Zhang Y. Optimized clinical practice for superaged patients with hip fracture: significance of damage control and enhanced recovery program. Burns Trauma. 2019;7(21.

https://doi.org/10.1186/s41038-019-0159-y

32. Yoon SH, Kim BR, Lee SY, Beom J, Choi JH, Lim JY. Influence of comorbidities on functional outcomes in patients with surgically treated fragility hip fractures: a retrospective cohort study. BMC Geriatr. 2021;21(1):283. https://doi.org/10.1186/s12877-021-02227-5

33. Li J, Xiao C, Yang H, Zhou Y, Wang R, Cao Y. Anemia and Iron Status Among Different Body Size Phenotypes in Chinese Adult Population: a Nation-Wide, Health and Nutrition Survey. Biological trace element research. 2018;185(1):1-10. https://doi.org/10.1007/s12011-017-1213-x

34. Chang W, Lv H, Feng C, et al. Preventable risk factors of mortality after hip fracture surgery: Systematic review and meta-analysis. International journal of surgery (London, England). 2018;52(320-328.

https://doi.org/10.1016/j.ijsu.2018.02.061

35. Toth E, Banefelt J, Åkesson K, Spångeus A, Ortsäter G, Libanati C. History of Previous Fracture and Imminent Fracture Risk in Swedish Women Aged 55 to 90 Years Presenting With a Fragility Fracture. Journal of bone and mineral research: the official journal of the American Society for Bone and Mineral Research. 2020;35(5):861-868. https://doi.org/10.1002/jbmr.3953

36. Folbert EC, Hegeman JH, Gierveld R, et al. Complications during hospitalization and risk factors in elderly patients with hip fracture following integrated orthogeriatric treatment. Arch Orthop Trauma Surg. 2017;137(4):507-515. https://doi.org/10.1007/s00402-017-2646-6

37. Hwang K-T, Moon J-K, Kim Y-H. Do we really need a surgery for hip fractures in elderly patients? Mortality rate and influencing factors. Arthroplasty. 2019;1(1):7. https://doi.org/10.1186/s42836-019-0009-1

38. Grossman DC, Curry SJ, Owens DK, et al. Interventions to Prevent Falls in Community-Dwelling Older Adults: US Preventive Services Task Force Recommendation Statement. Jama. 2018;319(16):1696-1704. https://doi.org/10.1001/jama.2018.3097

39. Filipov OB. Biplane Double-supported Screw Fixation of Femoral Neck Fractures: Surgical Technique and Surgical Notes. J Am Acad Orthop Surg. 2019;27(11):e507-e515. https://doi.org/10.5435/jaaos-d-17-00117

40. Shi H, Xiao L, Wang Z. Curative effect of artificial femoral head replacement and its effect on hip joint function and complications of senile patients with femoral intertrochanteric fracture. Experimental and therapeutic medicine. 2018;16(2):623-628. https://doi.org/10.3892/etm.2018.6214

41. Cai R, Tang J, Deng C, et al. Violence against health care workers in China, 2013-2016: evidence from the national judgment documents. Human Resources for Health. 2019;17(1):103. https://doi.org/10.1186/s12960-019-0440-y 
42. Sobolev B, Guy P, Sheehan KJ, et al. Mortality effects of timing alternatives for hip fracture surgery. Cmaj. 2018;190(31):E923-e932. https://doi.org/10.1503/cmaj.171512

43. Klestil T, Röder C, Stotter $C$, et al. Impact of timing of surgery in elderly hip fracture patients: a systematic review and meta-analysis. Scientific reports. 2018;8(1):13933. https://doi.org/10.1038/s41598-018-32098-7

44. Merloz P. Optimization of perioperative management of proximal femoral fracture in the elderly. Orthop Traumatol Surg Res. 2018;104(1s):S25-s30. https://doi.org/10.1016/j.otsr.2017.04.020

45. Chen M, Zhang Y, Du Y, et al. Epidemiological and clinical study of hip fracture in hospitalized elderly patients in Shanghai, China. Arch Osteoporos. 2019;14(1):37. https://doi.org/10.1007/s11657-019-0580-7

46. Zuo D, Jin C, Shan M, Zhou L, Li Y. A comparison of general versus regional anesthesia for hip fracture surgery: a metaanalysis. International journal of clinical and experimental medicine. 2015;8(11):20295-20301.

47. WANG X, SUN T, ZHANG J, ZHAO J. Predictive value of American Society of Anesthesiologists classification on prognosis of elderly patients with hip fracture. Chinese Journal of Trauma. 2020;51-57.

48. Weycker D, Li X, Barron R, Bornheimer R, Chandler D. Hospitalizations for osteoporosis-related fractures: Economic costs and clinical outcomes. Bone reports. 2016;5(186-191. https://doi.org/10.1016/j.bonr.2016.07.005

49. Pajulammi HM, Pihlajamäki HK, Luukkaala TH, Jousmäki JJ, Jokipii PH, Nuotio MS. The Effect of an In-Hospital Comprehensive Geriatric Assessment on Short-Term Mortality During Orthogeriatric Hip Fracture Program-Which Patients Benefit the Most? Geriatric Orthopaedic Surgery \& Rehabilitation. 2017;8(4):183-191.

https://doi.org/10.1177/2151458517716516

50. Yoo J, Lee JS, Kim S, et al. Length of hospital stay after hip fracture surgery and 1-year mortality. Osteoporos Int. 2019;30(1):145-153. https://doi.org/10.1007/s00198-018-4747-7

51. De Rui M, Veronese N, Manzato E, Sergi G. Role of comprehensive geriatric assessment in the management of osteoporotic hip fracture in the elderly: an overview. Disability and rehabilitation. 2013;35(9):758-765.

https://doi.org/10.3109/09638288.2012.707747

52. Ibarra Cornejo JL, Fernández Lara MJ, Aguas Alveal EV, Pozo Castro AF, Antillanca Hernández B, Quidequeo Reffers DG. Efectos del reposo prolongado en adultos mayores hospitalizados \%J Anales de la Facultad de Medicina.

2017;78(439-444.

53. Institute of Statistics and Cartography of Andalusia. Wages in Andalusia: Year 2019. Available from: https://www.juntadeandalucia.es/institutodeestadisticaycartografia/vidaslaborales/salarios/notaprensa.htm.

54. Shaanxi Provincial Bureau of Statistics. Average salary of staff. Available from: http://tjj.shaanxi.gov.cn/upload/2020/pro/3sxtjnj/zk/indexch.htm.

55. Civinini R, Paoli T, Cianferotti L, et al. Functional outcomes and mortality in geriatric and fragility hip fractures-results of an integrated, multidisciplinary model experienced by the "Florence hip fracture unit". Int Orthop. 2019;43(1):187-192. https://doi.org/10.1007/s00264-018-4132-3

56. Dubljanin-Raspopović E, Marković-Denić L, Marinković J, Nedeljković U, Bumbaširević M. Does early functional outcome predict 1-year mortality in elderly patients with hip fracture? Clinical orthopaedics and related research. 2013;471(8):2703-2710. https://doi.org/10.1007/s11999-013-2955-1

57. Azagra R, López-Expósito F, Martin-Sánchez JC, et al. Changing trends in the epidemiology of hip fracture in Spain. Osteoporos Int. 2014;25(4):1267-1274. https://doi.org/10.1007/s00198-013-2586-0

\section{Supplementary Files}

This is a list of supplementary files associated with this preprint. Click to download.

- AnnexDATABASECOLLECTIONSHEET.docx

Page 20/20 